\title{
Discharge Characterization and Variability Determination along Shorter Sections of Soaker Hose Pipe for Soil Column Experiment Abdullahi Salisu' ${ }^{1,3 *}$, Aimrun Wayayok ${ }^{1,2}$, Ahmad F. Abdallah ${ }^{1,2}$ \& Rowshon Md. Kamal $^{1,2}$ \\ ${ }^{1}$ Department of Biological and Agricultural Engineering, Faculty of Engineering, Universiti Putra Malaysia, 43400, UPM, Serdang, Malaysia \\ ${ }^{2}$ SMART Farming Technology Research Center, Faculty of Engineering, Universiti Putra Malaysia, 43400, UPM, Serdang, Malaysia \\ ${ }^{3}$ Department of Soil Science and Agricultural Engineering, Faculty of Agriculture, Usmanu Danfodiyo University, PMB 2346, Sokoto, Nigeria. \\ *Corresponding author E-mail: abdullahiskiru@gmail.com
} Received 29 September 2019; Accepted 20 May 2021; Available online 20 August 2021

\begin{abstract}
Unlike other micro-irrigation facilities like a drip, trickle, and sprinklers that emits water at regularly spaced intervals with predefined discharges, porous rubber pipes (soaker hose) has openings of variable sizes that become unevenly spaced with uneven distribution. The latter makes discharge to be variant along its lateral. Shorter sections are used under laboratory column experiments of soil wetting pattern studies and for this reason, laboratory experiments were conducted to evaluate the extent of emission rates variability on short sections of commercial Irrigation Soaker Hose, $16 \mathrm{~mm}$ diameter. Three sections of $10 \mathrm{~cm}$ length pipes were randomly selected from 15 no's cuts from different parts of the twenty meters length pipe bundle and used to investigate the extent of variability on emission rates characteristics under six different operating pressures. The result was achieved by collecting and measuring water emitted through the pipe sections at pre-determined pressures. The various discharges, coefficient of variation, and pressuredischarge curves of the section of the pipe then determined from the data. The result shows somewhat similar trends on the increase for water collected with an increase in pressures; however, when statistically compared, the discharges among the pipe sections vary. The values of Coefficient of Variation (CV) are less than $10 \%$ as the values $\mathrm{CV}$ range from $0.92 \%$ to $5.82 \%$, which is within a good category, according to ASAE Standard EP405.1 of $0-10 \%$. The findings indicate that, despite variations among the investigated sections, it can use any part as a representative unit in the soil column experiments with reasonable accuracy.
\end{abstract}

Keywords: Porous pipe, Coefficient of variation, Discharge, Short section, Pressure.

\section{Introduction}

Over the past decades, irrigation practice utilizes a large amount of fresh water to satisfy crops' water requirements. Irrigation consumes between 70 to $90 \%$ of total global freshwater, depending on the climatic condition of countries (Kulkarni, 2011). High demand from non-agricultural sectors of human endeavours, leads to so much pressure on available waters, which necessitates the use of alternatives and efficient irrigation measures 
that can guarantee a reduction in irrigation water consumption while realizing optimum crop production. These lead to the use of micro-irrigation techniques with high potentials on conserving water. Others are irrigation efficiency improvement, reduction in soil evaporation and drainage losses, create and maintain soil moisture conditions for crop growth ( Batchelor et al., 1996; Barragan et al., 2010; Kanda et al., 2019; Kimutai et al., 2018), which make it a good option in today irrigation practice. Porous pipe is one of such techniques used, with commercially marketed 'leaky pipe' or 'soaker hose' becoming popular in different parts of the world, and with particular emphasis in arid and semi-arid regions (Janani et al. 2011). Porous pipes made up of recycled tire and polyethene are mould into tubes under the influence of heat and pressure. These pipes emit as it conveys water along its entire circumference through closely spaced openings to irrigate the crops (Amin \& Islam, 1994; Amin et al., 1998; Teeluck \& Sutton, 1998; Haijun et al., 2009). As the openings (pores) are irregularly arranged, with variables sizes, the pipe tends to have variable emission rates and random distribution along with the lateral (Janani et al., 2011; Patel et al., 2011; Makavana et al., 2018). As mechanical production processes of pipes offer little or no control over size, distribution and spaces, laboratory and field tests indicate that pipes emission rates declined initially and gradually attend a stable emission rate (Janani et al., 2011). Other findings on distribution uniformity reported various coefficient of variations over different lengths of porous pipes, especially under field conditions. These make uniformity of water distribution a function of pressure variation and flow characteristics of the emission devices.

To evaluate hydraulic performances, researchers used different lengths of porous rubber pipe (soaker hose) ranging from less than a meter to $200 \mathrm{~m}$. In the ninetieth, Burt \& Styles (1994) found considerable variations in discharge per meter length of porous pipes with discharge characteristic curves exponent greater than 1.0, and attributed pipe low distribution uniformity to the smaller internal diameter and high friction loss. Yoder \& Mote (1995) found 9-15\% as the coefficient of variation on $6 \mathrm{~m}$ pipe length. Sohrabi \& Gazori (1997) mentioned flow to be a function of pressure on their analysis of various pipe lengths experiment placed at a depth of $0.4 \mathrm{~m}$ and spaced $0.6 \mathrm{~m}$. On pressure-discharge relationship and friction studies, (Amin et al., 1998) found exponent values in the range of 1.07 to 1.67 with the flow highly sensitive to pressure. Similarly, Teeluck \& Sutton (1998) examined $6 \mathrm{~m}$ long porous pipe at an operating pressure of 10 and $20 \mathrm{kPa}$ using filtered and non-filtered waters, and found discharge rate to decrease with time for filtered water but remain constant with non-filtered water. The authors reported coefficients of variation of 20 $\%$ to $35 \%$ with increasing values for filtered water with time. Akhoond-Ail \& Golabi (2008) discovered a variation of water application of 3.21 to $23.52 \%$ at $20 \mathrm{kPa}$ and 12.52 to $15.36 \%$ at $30 \mathrm{kPa}$ pressure head, respectively and coefficient and exponent of pressure- discharge curve to be 28.70 and 0.1871 . The authors also stated moisture to moves $10 \mathrm{~cm}$ up the soil column on lighttextured soil for horizontal porous pipes placed at a depth of $30 \mathrm{~cm}$ and applied water for 30 to $300 \mathrm{~min}$ at 4, 6, 8 and $10 \mathrm{~m}$ heads. Haijun et al. (2009) used two different diameter pipes. They found emission rates to decrease drastically at the initial stage, with minimum coefficient variation reached within the operating pressure range of $50 \sim 60 \mathrm{kPa}$. Patel et al. (2011) considered four laterals of $12 \mathrm{~mm}$ diameter, buried at 15-30 cm depth and spaced $0.6 \mathrm{~m}$ 
operated at 20 and $30 \mathrm{kPa}$ pressure head. Makavana et al. (2018) investigated the emitting rate variation for 30,45 and $60 \mathrm{~m}$ porous pipes operated at 2, 4 and $6 \mathrm{~m}$ to be 6.57 to $18.83 \%, 17.32$ to $21.93 \%$ and 23.05 to $25.49 \%$, respectively. The percentage flow variation increases with increased in pressure head, which results to increases in pipe emission, frictional losses and head variation within porous pipe length.

The above research findings were for various sizes of longer pipes. However, in laboratory experiments, for soil-wetting pattern study, shorter lateral sections are usually used. Therefore, this research focused on investigating the characteristic behaviours of shorter laterals with closed end caps, on studying the pressure-discharge relation and coefficient of variation. Thus, this study reported findings as relates to emission rates variations, pressure-discharge relationship along shorter pipe sections.

\section{Materials \& Methods:}

The research was conducted at Irrigation, Drainage Engineering and Infrastructure Laboratory of the Department of Biological and Agricultural Engineering, Universiti Putra Malaysia, to study the characteristics performance of shorter lengths of porous rubber pipe. The materials used for the test experiments include: tap in the lab as the water source, 20 meters length rubber porous pipe (soaker hose) bundle of product ID
14531981510 of $16 \mathrm{~mm}$ inside diameter and 22 $\mathrm{mm}$ outside diameter. Others are pressure gauges, hose tube, clips, beakers, measuring cylinders, stopwatch, Stainless steel pan, 16 $\mathrm{mm}$ stop end plugs, tees and adaptors.

Fifteen number cuts pieces (placed inside box container) of $10 \mathrm{~cm}$ lengths sections from different parts of $20 \mathrm{~m}$ bundle of soaker hose porous pipe, shuffled and drawn at random each without replacement from the box to give an unbiased selection for the experiment. The experimental setup consists of water from the source, flexible tube and, pressure gauge to set and monitor the pressure by controlling the flow in the porous pipe cut sections. In establishing pressure-discharge curves relationship of the short pipe segments, the volume of water discharged from the pipe section under the different pressure range of 0.5 bar to 3.0 bars at an interval of 0.5 bar were monitored. The lengths of pipe are kept at somewhat smaller $(10 \mathrm{~cm})$, so that friction losses can be neglected. The water emitted from each of the pipe sections were collected at every 5 minutes interval using $300 \mathrm{ml}$ beakers and measured using measuring cylinders of $50 \mathrm{ml}$ and $500 \mathrm{ml}$. The process repeated 12 times, and these give a total of 1 hour for six different pressure levels to complete a set round of a test. Six operating pressure $\times 12$ collection cycles $\times 3$ repeated segments. Fig (1) diagrammatically explained the experimental setup and the process. 
Abdullahi et al. / Basrah J. Agric. Sci., 34(Special Issue 1): 92-99, 2021

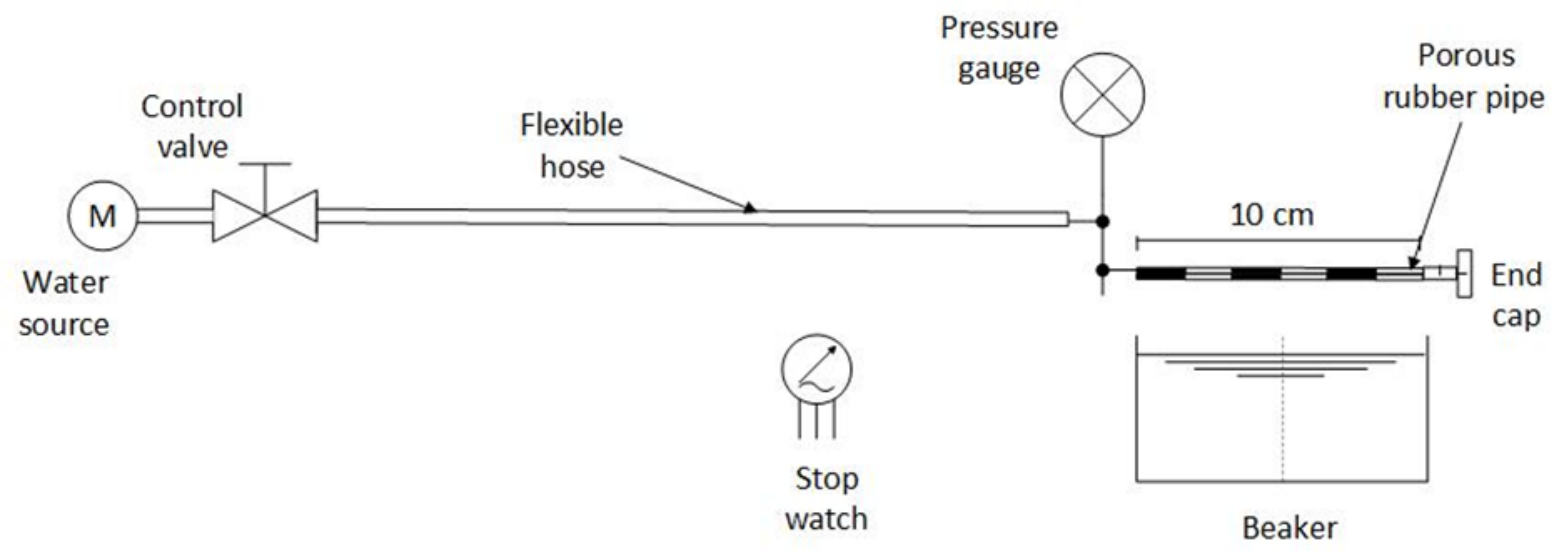

Fig. (2): Schematic illustration of the experimental setup

Two important discharge evaluation parameters, pipe emission rate (ER) and coefficient of variation (CV), were determined using the following equations and IBM SPSS

$$
q=c h^{x}
$$

Where: $\mathrm{q}$ is pipe discharge rate; $\mathrm{c}$ is pipe constant; $h$ - operating pressure and $\mathrm{x}$ is an exponent of pressure -discharge curve.

$$
C V=\left(\frac{S}{\bar{q}}\right) \times 100 \%
$$

Where: $\bar{q}$ - the average discharge through pipe section; S- standard deviation.

\section{Results \& Discussion:}

\section{Volume of water}

At the initial stage, all the sections tested relatively have recorded a higher volume of water collection. However, as the monitoring process continues, the volume assumed relatively constant values with little differences. Water collected from $10 \mathrm{~cm}$ pipe sections were monitored at $5 \mathrm{~min}$ time interval at $0.5,1,1.5,2,2.5$ and 3 bar. Subsequently evaluated the effect of pressure variations on pipe discharge. Water collected from each section under these different pressure levels for one hour (twelve times), and an average taken as for the volumes recorded. The statistics 23 and inferential statistics for results analyses. The general discharge - pressure relationship as a power function as illustrated in Eq. (1) (Jin et al., 2015)

Coefficient of variation (CV) of the emission rate of the pipe calculated using Eq. (2):

discharge rate and coefficient of variation on different pressure levels on pipe sections RPP1, RPP2, and RPP3 were calculated. Table (1) shows the average volume and fig (2) the trend of water collection on all the pipe sections and pressure - discharge curves plots, as presented in fig (3).

Fig. (2), revealed as pressure increases, there is a general increase for water collected from all the pipes. The trend though not uniformly the same among the pipes, for each pressure increment, there is corresponding increasing water released from each pipe. 
Table (1): Volume of water $(\mathrm{ml})$ collected under different applied pressures.

\begin{tabular}{rrrrrrr}
\hline \multirow{2}{*}{ section label } & \multicolumn{7}{c}{ Pressure (bar) } \\
\cline { 2 - 7 } & $\mathbf{0 . 5}$ & $\mathbf{1 . 0}$ & $\mathbf{1 . 5}$ & $\mathbf{2 . 0}$ & $\mathbf{2 . 5}$ & $\mathbf{3 . 0}$ \\
\hline RPP1 & 74.9 & 194.5 & 333.1 & 406.5 & 611.0 & 722.5 \\
\hline RPP2 & 87.5 & 141.5 & 243.0 & 329.5 & 532.6 & 747.0 \\
\hline RPP3 & 63.2 & 92.1 & 219.0 & 429.0 & 602.5 & 707.0
\end{tabular}

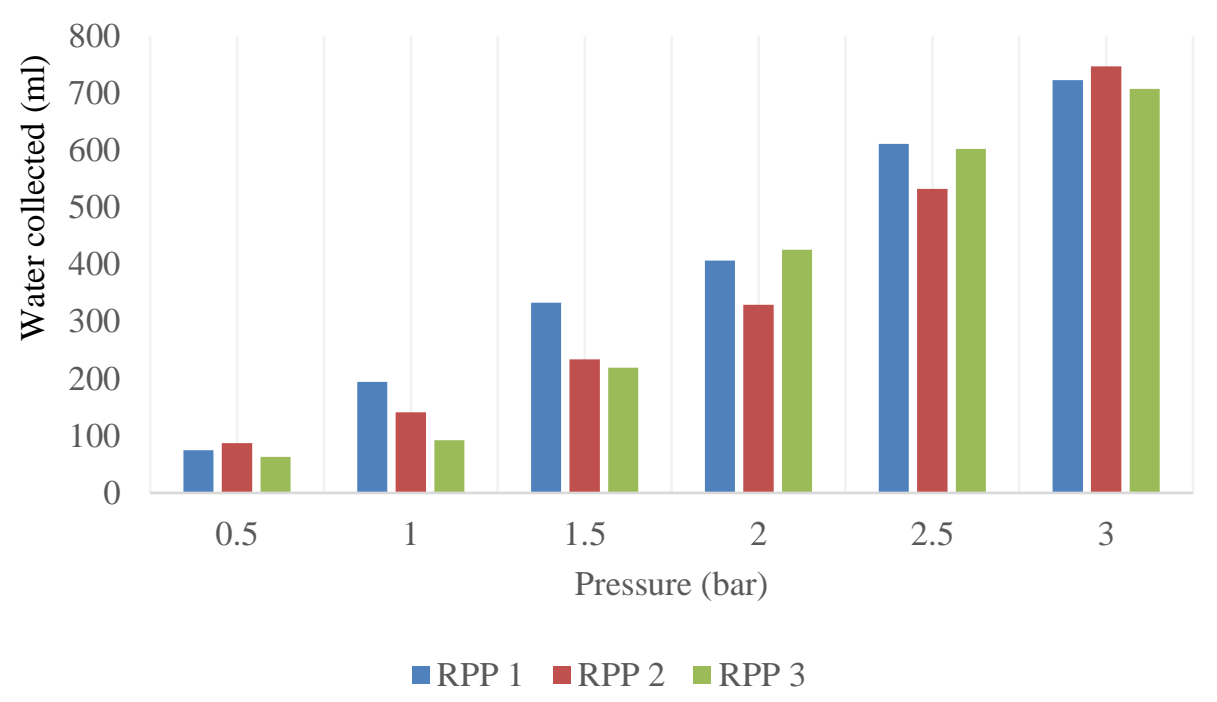

Fig. (2): Chart showing trends on water collection among the pipe sections.

\section{Pressure-discharge curves}

In evaluating the effect of pressure on volume discharged, the pipes sections were tested at $0.5,1,1.5,2,2.5$, and 3 bar pressure levels. The results of the discharge rate are the average value of all measured water collected for 5 minutes for an hour gives 12 measurements for each pressure level. These provide a total of 18 hours of the effective measurement period. Figure 3 shows the pressure - discharge curves of pipe sections.

The coefficients and exponents of pressuredischarge curves for the pipe sections evaluated are $0.8279,0.7307,0.4743$, and $0.855,1.0494,0.8418$, respectively. $\mathrm{R}$ - values determine how well regression models fit the observed data. From the r-squares values of $0.9168,0.9565$, and 0.9934 , it indicates a better fit for all the models of the observed sections, showing strong relation between pressure and discharge variables with 91.68 , 95.65 and $99.34 \%$ of the data fitting the models for RPP1, RPP2 and RPP3 respectively. To compare pipe discharge at different pressure levels between the pipes sections, analysis of variance (ANOVA) with post hoc Tukey test was performed were discharge values are normally distributed. Where not found not normal an appropriate transformation, perform Kruskal Wallis H-test with Wilcoxon rank-sum test. 


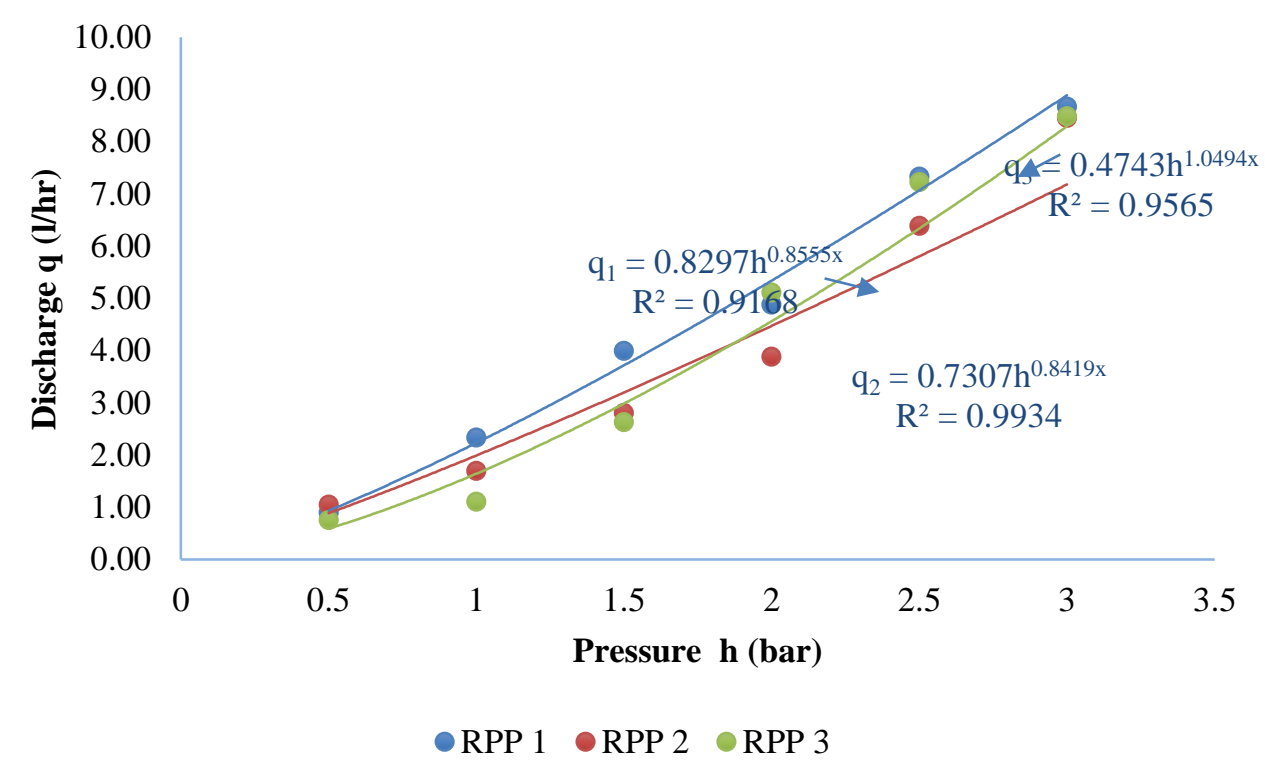

Fig. (3): Pressure - discharge curves for all the tested pipe sections.

At 0.5 bar, the discharge values for all the pipe sections are normally distributed and performed a parametric test. The one-way independent ANOVA indicated that the discharge at 0.5 bar differed significantly between all the pipes1, 2 and $3, \mathrm{~F}(2,27)=$ 18.505, $\mathrm{p}<.001$. A post-hoc (Tukey) test indicated that RPP1 is significantly lower than RPP2 ( $<$.001) and RPP3 ( $=.001)$. An independent one-way ANOVA indicated that the emission rate at 1.0 bar differed significantly among all the pipe sections, F (2, $27)=281.347, \mathrm{p}<.001$. A post-hoc (Tukey) test shows that discharge at RPP2 is significantly lower than RPP1 $(\mathrm{p}<.001)$ and RPP3 ( $<$.001). At 1.5 bars, all treatments are non-normally distributed; hence, perform nonparametric (Kruskal Wallis H) test. The result indicates that at 1.5 bar, discharges differed significantly among the pipes, $\mathrm{X}^{2}=24.956, \mathrm{p}$ $<.001$. When post-hoc (Pairwise Wilcoxon rank-sum test) was performed, it further indicated that RPP2 is significantly lower than RPP3 ( $\mathrm{p}=.019)$ and RPP1 $(\mathrm{p}<.001)$ respectively.
At 2.0 bars, most treatments are nonnormally distributed and performed a nonparametric test. Kruskal Wallis H-test indicated that the discharges differed significantly according to pipes 1,2 , and $3, \mathrm{X}^{2}$ $=26.209, \mathrm{p}<.001$. A post-hoc (Pairwise Wilcoxon rank-sum test) indicated that the difference is between all the pipes with RPP2 discharge significantly been lower than RPP1 $(p=.031)$ and RPP3 $(p<.001)$ whereas RPP1 discharges lower than RPP3 ( $\mathrm{p}=.031)$. At 2.5 bar, RPP1 shows a strong significance of nonnormality. Therefore, a non-parametric test conducted, and A Kruskal Wallis $\mathrm{H}$ test showed that water discharge at 2.5 bar differed significantly among the pipe sections. $\mathrm{X}^{2}=$ $25.443, \mathrm{p}<.001$. Likewise, when post-hoc (Pairwise Wilcoxon rank-sum test) was performed, it indicated that the differences are between all pipe treatments with RPP2 discharge significantly lower than RPP1 ( $\mathrm{p}=$ $.027)$ and RPP3 ( $<.001)$ and RPP1 discharge significantly lower than RPP3 discharge ( $\mathrm{p}=$ .046). RPP2 shows to be significantly nonparametric, so the Kruskal Wallis $H$ test performed. It showed that water discharge at 
3.0 bar differed significantly according to 1,2 and 3 with $X^{2}=26.663, \mathrm{p}<.001$ and similarly when post-hoc (Pairwise Wilcoxon rank-sum test) was performed it showed that the difference in discharge is between RPP1 and RPP3 ( $<$.001), and between RPP2 and RPP3 $(\mathrm{p}=.015)$. Generally, the higher the pressure, the more discharge through the pipes become random without normality. Impliedly, to achieve better water distribution, the operating pressure of the pipes need to be lower.

\section{Conclusions}

The studies reported the effects of pressure variation on discharge rate and coefficient of variation of shorter (10 cm segment) sections of porous pipe (soaker hose). Water collections made at intervals of 5 minutes for a period of 1 hr over a range of six different pressures from 0.5 - 3.0 bars, The experiments conducted on three randomly selected sections, from 15 number cuts sections from different parts of 16 $\mathrm{mm}, 20 \mathrm{~m}$ porous pipe bundle. The volume of water, average discharge, coefficient of variation, and pressure - discharge curves for each section were determined and statistically analyzed. For all the three pipes, the results showed that there was an increase in the volume of water collected with a corresponding increase in pressure, even though there were no definite constant trends among the pipes at the same applied pressures. The exponents' values of pressure- discharge curves for RPP1, RPP2, and RPP3 pipe sections are $0.85,0.84,1.04$, with R2 (determination coefficient) values of 0.9168 , 0.9934 and 0.9565 , respectively, indicating a strong correlation among all the variables. Coefficients of variation (CV) of all the pipes at different pressures ranged between 0.92 to $5.58 \%$, which is within a $10 \%$ limit. Therefore, this shows that any part of the pipe used as a representative entity to conduct wetting pattern studies and the results obtained from work can be useful in the design, operation, and management of soaker hose porous pipe irrigation system.

\section{Acknowledgement}

This research work was financially supported by the Nanomite-LRGS program (grant No.9443105), through the Department of Biological and Agricultural Engineering, Faculty of Engineering Universiti Putra Malaysia. The authors are grateful for this support.

\section{References}

Akhoond-Ail, A. M., \& Golabi, M. (2008). Subsurface porous pipe irrigation with vertical option as a suitable irrigation method for light soils. Asian Journal of Scientific Research, 1, 180-192. https://dx.doi.org/10.3923/ajsr.2008.180.192

Amin, M. S. M., \& Islam, F. (1994). Porous pipes as subsurface microirrigation laterals (No. F10700). Serdang, $\quad$ Selangor. $1 \mathrm{p}$ http://psasir.upm.edu.my/id/eprint/42788/1/Porous\% 20pipes $\% 20$ as $\% 20$ subsurface $\% 20$ microirrigation $\% 2$ Olaterals.pdf

Amin, M. S. M., Lim, C. W., \& Zakaria, A. A. (1998). Flow characteristics of a porous pipe irrigation lateral. Pertanika Journal of Science \& Technology, 6, 3746.

http://psasir.upm.edu.my/id/eprint/3419/1/Flow_Cha racteristics_of_a_Porous_Pipe_Irrigation_Lateral.pdf

Barragan, J., Cots, L., Monserrat, J., Lopez, R., \& Wu, I. P. (2010). Water distribution uniformity and scheduling in micro-irrigation systems for watersaving and environmental protection. Biosystem Engineering, 107, 202-211. https://doi.org/10.1016/j.biosystemseng.2010.07.009

Batchelor, C., Lovell, C., \& Murata, M. (1996). Simple microirrigation techniques for improving irrigation efficiency on vegetable gardens. Agricultural Water Management, 32 , 37-48. https://doi.org/10.1016/S0378-3774(96)01257-7

Burt, C. M., \& Styles, S. W. (1994). Drip and microirrigation for trees, vines and row crops. Cal Poly, San Luis Obispo. 261pp. 


\section{Abdullahi et al. / Basrah J. Agric. Sci., 34(Special Issue 1): 92-99, 2021}

Haijun, L., Zuoxin, L., Qiaosheng, S., \& Guanghua, Y. (2009). Effects of operating pressure on the discharge characteristics of porous pipes as micro-irrigation laterals. Transactions of the CSAE, 25, 2-6. https://www.cabdirect.org/cabdirect/abstract/200931 49742

Janani, A., Sohrabi, T., \& Dehghanisanji, H. (2011). Pressure variation impact on discharge characteristics of porous pipes. In 8th International Micro Irrigation Congress: Innovation in Technology and Management of Micro-irrigation for Crop Production Enhancement (pp. 284-296). Tehran, Iran. http://wgon-farm.icidonline.org/micro_irrigation_tehran.pdf

Jin, J., Huanfang, L., \& Tao, D. (2015). The calculation on discharge capacity of the porous pipe. Advance Materials Research, 1065-1069, 650-657. https://doi.org/10.4028/www.scientific.net/AMR.106 5-1069.650

Kanda, E. K., Niu, W., Mabhaudhi, T., \& Senzanje, A. (2019). Moistube Irrigation Technology: A Review. Agricultural Research, 9, 139-147. https://link.springer.com/article/10.1007/s40003019-00448-0

Kimutai, E. K., Mabhaudhi, T., \& Senzanje, A. (2018). Hydraulic and clogging characteristics of Moistube irrigation as influenced by water quality. Journal of Water Supply: Research and Technology, 67, 438446. https://doi.org/10.2166/aqua.2018.166
Kulkarni, S. (2011). Innovative technologies for water saving in irrigated agriculture. International Journal of Water Resources and Arid Environments, 1, 226231.https://www.psipw.org/attachments/article/304/I JWRAE_1(3)226-231.pdf

Makavana, J., Deraari, J., \& Mashru, H. (2018). Pressure variation effect on discharge characteristics of porous pipe develop the pressure discharge relationship of porous pipe. Beau Bassin: LAP LAMBERT Academic Publishing. 72pp. Retrieved from https://www.amazon.com/Pressure-VariationEffect-Discharge-Characteristics/dp/6139928737

Patel, G. R., Ghaghada, R. H., \& Chalodia, A. L. (2011). Hydraulics performance evaluation of porous pipe (Subsurface) irrigation system. International Journal of Agricultural Engineering, 4, 156-159. http://researchjournal.co.in/upload/assignments/4_15 6-159.pdf

Sohrabi, T., \& Gazori, N. (1997). Subsurface irrigation with porous pipe. Iranian Journal of Agricultural Science, 28, 145-156.

Teeluck, M., \& Sutton, B. G. (1998). Discharge characteristics of a porous pipe microirrigation lateral. Agricultural Water Management, 38, 123-132. https://doi.org/10.1016/S0378-3774(98)00060-2

Yoder, R., \& Mote, C. (1995). Porous pipe discharge uniformity. In L. F. R. (Ed.), 5th International Microirrigation Congress Orlando, Florida, 750-755. 